\title{
Interleukin-1 $\beta$ induced nuclear factor- $\kappa B$ binds to a disintegrin-like and metalloproteinase with thrombospondin type 1 motif 9 promoter in human chondrosarcoma cells
}

\author{
AYNUR ALTUNTAS ${ }^{1 *}$, SEVIL OSKAY HALACLI $^{2 *}$, OZLEM CAKMAK $^{3}$, GONUL ERDEN $^{4}$, \\ SUMEYYA AKYOL $^{5}$, VELI UGURCU ${ }^{6}$, SATOSHI HIROHATA ${ }^{7}$ and KADIR DEMIRCAN ${ }^{5}$ \\ ${ }^{1}$ Division of Chemistry, Ankara Regional Office of Council of Forensic Medicine, Ankara 06100; \\ ${ }^{2}$ Pediatric Immunology Unit, Institute of Children's Health, Hacettepe University, Ankara 06100; \\ ${ }^{3}$ Faculty of Education, Division of Biology Education, Gazi University, Ankara 06500; \\ ${ }^{4}$ Department of Clinical Biochemistry, Medical Faculty, Hacettepe University, Ankara 06100; \\ ${ }^{5}$ Department of Medical Biology, Turgut Ozal University School of Medicine, Ankara 06105; \\ ${ }^{6}$ Department of Medical Biochemistry, Dumlupinar University Medical Faculty, Kutahya 43100, Turkey; \\ ${ }^{7}$ Okayama University Graduate School of Medicine, Dentistry and Pharmacological Sciences, \\ Okayama 700-8558, Japan
}

Received May 9, 2014; Accepted January 21, 2015

DOI: $10.3892 / \mathrm{mmr} .2015 .3444$

\begin{abstract}
Nuclear factor- $\mathrm{\kappa B}(\mathrm{NF}-\mathrm{\kappa B})$ is involved in the regulation of inflammation-associated genes. NF- $\mathrm{KB}$ forms dimers which bind with sequences referred to as NF-kB sites (9-11 bp). A disintegrin-like and metalloproteinase with thrombospondin type 1 motif 9 (ADAMTS9) is a type of proteoglycanase, which proteolytically cleaves versican and aggrecan. ADAMTS9 is a cytokine-inducible gene that contains binding sites for NF- $\mathrm{\kappa B}$ within its promoter region. Interleukin-1 $(\mathrm{IL}-1 \beta)$ affects cartilage metabolism and is involved in the NF- $\mathrm{KB}$ pathway. It is therefore hypothesized that NF- $\mathrm{kB}$ binding with ADAMTS9 promoters may activate IL-1 $\beta$, thereby promoting chondrocytic cell growth. In the present study, the OUMS-27 chondrocytic human chondrosarcoma cell line was treated with IL-1 $\beta$ with or without inhibitors of NF- $\mathrm{kB}$ signaling pathways. Chromatin immunoprecipitation (ChIP) and electromobility shift assays (EMSA) were conducted order to analyze the binding of NF- $\mathrm{kB}$ with the ADAMTS9 promoter region. NF- $\mathrm{kB}-\mathrm{p} 65$ subunit phosphorylation was promoted in IL-1 $\beta$-treated cells, which were not treated with inhibitors of NF- $\mathrm{kB}$ signaling pathways. By contrast, NF- $\mathrm{KB}-\mathrm{p} 65$ subunit phosphorylation was inhibited in cells that had been treated with BAY-117085, an NF- $\kappa B$
\end{abstract}

Correspondence to: Dr Kadir Demircan, Department of Medical Biology, Turgut Ozal University School of Medicine, 16/A Gimat, Ankara 06105, Turkey

E-mail: kdemircan1@gmail.com

${ }^{*}$ Contributed equally

Key words: a disintegrin-like and metalloproteinase with thrombospondin type 1 motif 9 , nuclear factor- $\kappa \mathrm{B}$, interleukin- $1 \beta$ pathway inhibitor. ChIP and EMSA assays demonstrated that, following treatment with IL-1 $\beta$, NF- $\mathrm{\kappa B}-\mathrm{p} 65$ bound to elements located at -1177 and -1335 in the ADAMTS9 promoter region, in contrast to the untreated samples. The results of the present study suggested that NF- $\kappa B$ may be involved in IL-1 $\beta$-induced activation of ADAMTS9 in human chondrocytes.

\section{Introduction}

A disintegrin and metalloproteinase with thrombospondin motifs (ADAMTSs) are secretory proteins that are involved in a variety of biological processes, such as angiogenesis, cell adhesion, proteolytic shedding and cell signaling. ADAMTS type 1 motif 9 (ADAMTS9) is involved in proteoglycan degradation $(1,2)$. IL-1 $\beta$ was found to induce ADAMTS9 gene expression in OUMS-27 chondrosarcoma cells in a previous investigation (3). ADAMTS9 gene expression was synergistically induced by a combination of IL-1 $\beta$ and tumor necrosis factor $\alpha$ (TNF $\alpha$ ), suggesting that the induction of ADAMTS9 may be associated with cartilage inflammation (4). The human ADAMTS9 promoter region contains nuclear factor of activated T cells c1 (NFATc1) consensus sites. Following treatment with IL-1 $\beta$, NFATc1 was activated in human chondrocytic cells (5). A previous investigation demonstrated that, following treatment with a combination of TNF and IL- $1 \beta$, the expression of activated activator protein 1 and $\mathrm{NF}-\kappa \mathrm{B}$ transcription factors was enhanced in human chondrocytic cells (6).

$\mathrm{NF}-\mathrm{\kappa B}$ is a pro-inflammatory transcription factor, the expression of which is activated by inflammatory cytokines such as TNF $\alpha$ and IL-1, and a number of chemokines (7-9). NF- $\kappa B$ activation may occur via classical or canonical pathways (10). NF- $\mathrm{KB}$ is composed of homodimers and heterodimers of five members of the Rel family, which exhibit different binding specificities, 
including p65/RelA, RelB, c-Rel, p50/p105 and p52/p100. One of the predominant types of heterodimers consists of p65 and p50 subunits. $\mathrm{NF}-\kappa \mathrm{B}$ is typically found in the cytoplasm. The nuclear factor of $\kappa$ light polypeptide gene enhancer in B-cells inhibitor (I $\mathrm{B}$ ) kinase complex (IKK complex) is composed of two catalytic subunits (IKK $\alpha$ and IKK $\beta$ ). The IKK complex binds with the regulatory subunit IKK $\gamma / \mathrm{NF}-\kappa \mathrm{B}$ essential modulator, which subsequently forms the TNF- $\alpha$ receptor complex, and promotes $\mathrm{I} \kappa \mathrm{B}$ phosphorylation. Phosphorylated $\mathrm{I} \kappa \mathrm{B}-\alpha$ is rapidly ubiquitinated and degraded via a proteasome pathway. Degradation of $\mathrm{I} \kappa \mathrm{B}-\alpha$ leads to the expression of $\mathrm{NF}-\kappa \mathrm{B}$, which translocates into the nucleus where it binds to specific binding sites within the promoter regions of target genes (9).

In the present study, the association between $N F-\kappa B$ and IL- $1 \beta$ stimulation was examined, and the involvement of $\mathrm{NF}-\kappa \mathrm{B}$ and IL-1 $\beta$ in ADAMTS9 promoter activation was analyzed in OUMS-27 cells.

\section{Materials and methods}

Antibodies and reagents. Mouse monoclonal antibodies against the phosphorylated NF-кB-p65 subunit (sc-33020; Santa Cruz Biotechnology, Inc., Dallas, TX, USA), total NF-кB-p65 (sc-372; Santa Cruz Biotechnology, Inc.) and IкB- $\alpha$ (9242; Cell Signaling Technology, Inc., Danvers, MA, USA) were used for western blot analysis at a dilution of 1:1,000. Recombinant human IL-1 $\beta$ and BAY 11-7085 were purchased from R\&D Systems, Inc. (Minneapolis, MN, USA) and EMD Millipore (Billerica, MA, USA), respectively. For the chromatin immunoprecipitation (ChIP) assay of the ADAMTS9 promoter region, a ChIP assay kit was used (Merck Millipore, Darmstadt, Germany). The primers used for ChIP and the conjugated oligonucleotides used for electromobility shift assays (EMSA) were purchased from Alpha DNA technologies (Montreal, Canada). A Light Shift chemiluminescence EMSA kit was purchased from Thermo Fisher Scientific (Waltham, MA, USA).

Cell cultures and cytokine treatment. The OUMS-27 human chondrosarcoma cell line was obtained from Okayama University Graduate School of Medicine Dentistry and Pharmacological Sciences (Okayama, Japan). Cells were maintained in Dulbecco's modified Eagle's medium-low glucose (Thermo Fisher Scientific) supplemented with $10 \%$ fetal calf serum (Thermo Fisher Scientific), $100 \mathrm{U} / \mathrm{ml}$ penicillin (Thermo Fisher Scientific) and $100 \mu \mathrm{g} / \mathrm{ml}$ streptomycin (Thermo Fisher Scientific) at $37^{\circ} \mathrm{C}$ in $5 \% \mathrm{CO}_{2}$. Cells were treated with or

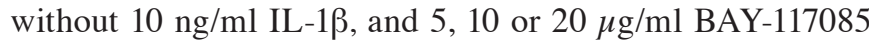
was added to the cultures.

Western blotting. Cell lysates were separated using $10 \%$ SDS-PAGE (Sigma-Aldrich, St. Louis, MO, USA) and transferred to polyvinylidene difluoride membranes (EMD Millipore). The membrane was treated with 5\% non-fat milk (Cell Signalling Technologies, Inc., Danvers, MA, USA) for $1 \mathrm{~h}$ at room temperature and probed with the p-NF- $\kappa$ B-p65 subunit, total NF- $\kappa$ B-p65 and IkB- $\alpha$ primary antibodies overnight at $4{ }^{\circ} \mathrm{C}$. The primary antibodies were detected using horseradish peroxidase (HRP)-conjugated anti-rabbit and anti-mouse secondary antibodies (IgG; Santa
Cruz Biotechnology, Inc.), and visualized using enhanced chemiluminescence (Thermo Fisher Scientific).

ChIP assay. ChIP analysis was performed according to the manufacturer's instructions (EMD Millipore). Following treatment with IL-1 $\beta$, OUMS-27 cells were fixed with $1 \%$ formaldehyde (Sigma-Aldrich) for $5 \mathrm{~min}$. The cells were lysed in SDS lysis buffer (Thermo Fisher Scientific). Subsequently the chromatin was sonicated to an average size of $0.5-1 \mathrm{~kb}$. Chromatin solutions were precipitated overnight at $4{ }^{\circ} \mathrm{C}$ using an anti-p65 antibody. Immune complexes were recovered using a salmon sperm DNA-saturated protein A agarose gel (EMD Millipore). In order to reverse the cross-linked and immunoprecipitated chromatin, solutions were incubated at $65^{\circ} \mathrm{C}$ overnight. DNA was extracted using phenol/chloroform (Sigma-Aldrich) and precipitated with ethanol (Sigma-Aldrich) following proteinase K (Sigma-Aldrich) treatment. PCR was conducted in order to amplify 205 and $260 \mathrm{bp}$ fragments of the ADAMTS9 promoter region (-1335/-1177), using the following PCR protocol: $96^{\circ} \mathrm{C}$ for $5 \mathrm{~min}$ and $96^{\circ} \mathrm{C}$ for $30 \mathrm{sec}$, followed by 30 cycles of $56^{\circ} \mathrm{C}$ for $30 \mathrm{sec}$ and $72^{\circ} \mathrm{C}$ for $40 \mathrm{sec}$. The primers for ADAMTS9 promoter regions (-1335 and -1177) were obtained from Alpha DNA Technologies, and are shown in Table I. SoniGenomic DNA (EMD Millipore), following sonification, was used as a positive control and immunoprecipitated DNA-conjugated mouse IgG (EMD Millipore) was used as a negative control for the experiments.

EMSA. EMSA was performed using the LightShift Chemiluminescent EMSA kit (Thermo Fisher Scientific), according to the manufacturer's instructions. Nuclear extracts were prepared from OUMS-27 cells and probed with HRP-conjugated DNA oligos, which were homologous to the consensus $\mathrm{NF}-\kappa \mathrm{B}$ site at -1335 upstream of the ADAMTS9 promoter region. A biotin-labeled 5'GGCTGAAAGCAAGCGGAAGTGATTGAGAAATCCCT CCAG3' oligo was used. Protein-DNA complexes were separated on a $6 \%$ polyacrylamide gel using electrophoresis. A super shift assay was performed using nuclear extracts pretreated with antibodies against the NF- $\mathrm{NB}-\mathrm{p} 65$ protein (as used in western blot analysis). The $\mathrm{NF}-\kappa \mathrm{B}$ competitor probe, a nonlabeled ("cold") oligonucleotide, was added in excess to be used as a negative control, and the $\mathrm{H} 4$ histone protein was used as a positive control (Thermo Fisher Scientific).

\section{Results}

$I L-1 \beta$-stimulated $N F-\kappa B$-p 65 phosphorylation is reversed by $B A Y$ 11-7085. A western blot analysis was performed in order to analyze NF- $\mathrm{BB}-\mathrm{p} 65$ phosphorylation following IL-1 $\beta$ treatment. According to results from gel electrophoresis, the level of expression of phosphorylated NF- $\kappa$ B-p65 in OUMS-cells was greater following $10 \mathrm{~min}$ of IL-1 $\beta$ treatment compared with that following $5 \mathrm{~min}$ of treatment (Fig. 1A). Following $30 \mathrm{~min}$ of IL-1 $\beta$ treatment, phosphorylated NF- $\kappa$ B-p65 expression levels had decreased. In the negative control cells (no IL-1 $\beta$ treat-

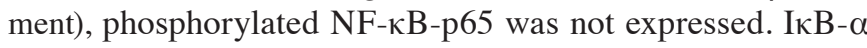
was expressed in the negative control OUMS-27 cells but not in the IL-1 $\beta$ treated OUMS-27 cells. Following treatment with BAY-117085 (an NF- $\mathrm{B}$ pathway inhibitor), the expression 
Table I. Primers used in the chromatin immunoprecipitation analysis.

\begin{tabular}{|c|c|c|c|}
\hline $\begin{array}{l}\mathrm{NF}-\kappa \mathrm{B} \text { consensus site } \\
\text { in ADAMTS } 9 \text { promoter }\end{array}$ & Sense $\left(5^{\prime}-3^{\prime}\right)$ & Antisense (3'-5') & $\begin{array}{l}\text { PCR product } \\
\text { (bp) }\end{array}$ \\
\hline-1335 & CCACTGAACCACCCAAGATT & GGAGTGTAAAGTTGTAGATCC & 205 \\
\hline-1177 & GGATCTACAACTTTACACTCC & TGGGGTTCTTAATCCTGCAGGTC & 260 \\
\hline-618 & GGAAAGGGAGAGAACTTTCC & TTCCAGACCATGTCCCCTCC & 196 \\
\hline-460 & GGAGGGGACATGGTCTGGAA & GGATAGCTGAGCGGCTTCTT & 402 \\
\hline-130 & AAGAAGCCGCTCAGCTATCC & CGCCAACTTTTGACTTTAGG & 258 \\
\hline
\end{tabular}

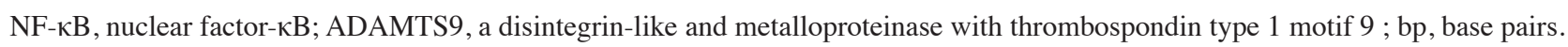

A
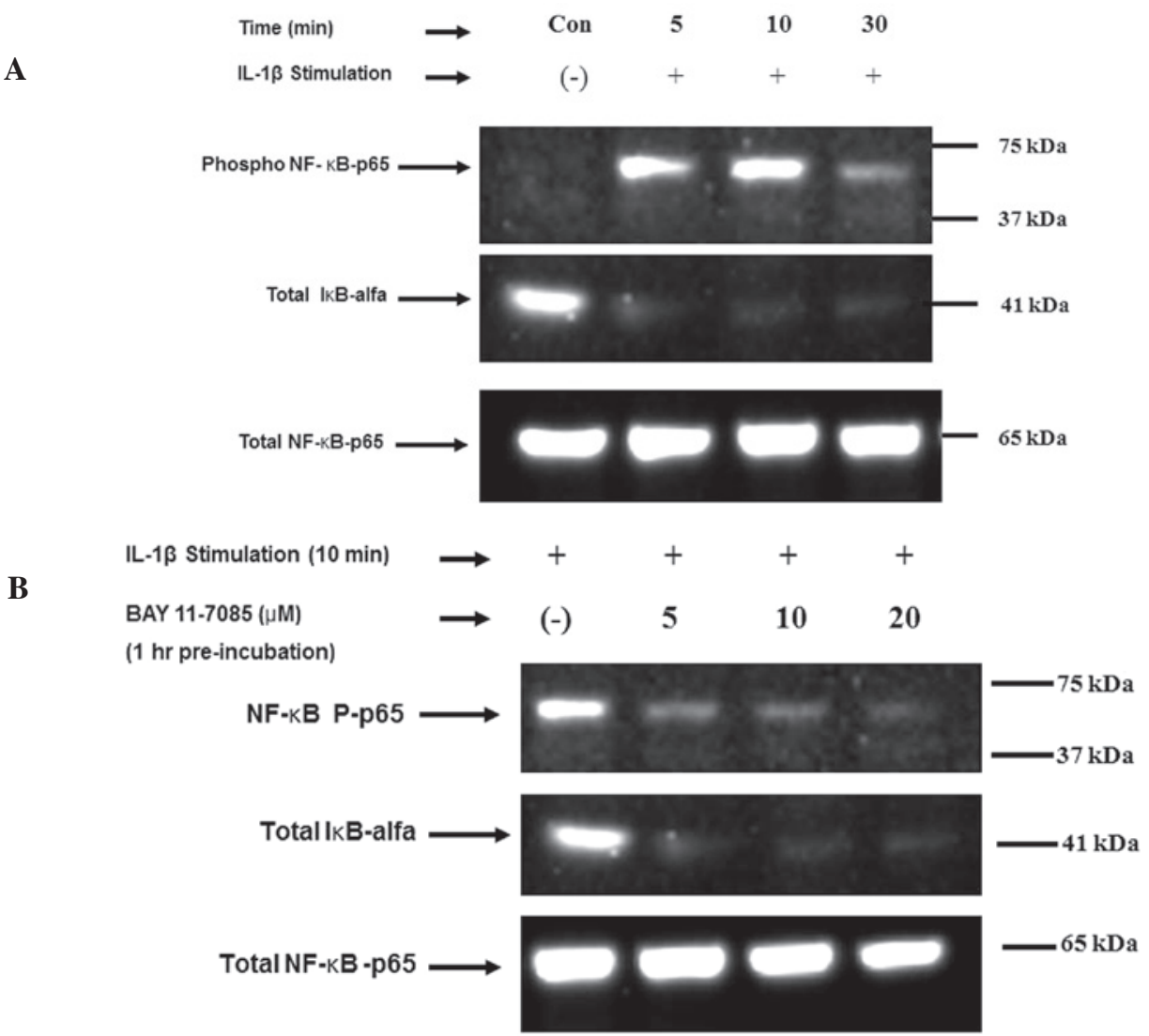

Figure 1. (A) p65 phosphorylation. OUMS-27 cells were stimulated with $10 \mathrm{ng} / \mathrm{ml} \mathrm{IL}-1 \beta$. Total cell extracts were immunoblotted with anti-phospho-p65,

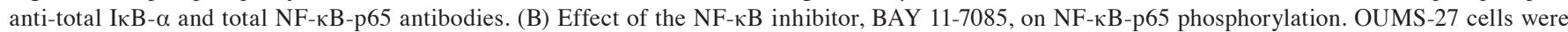

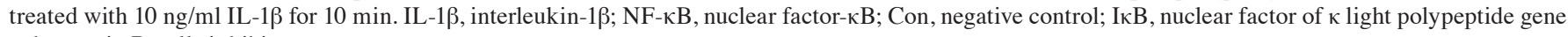
enhancer in B-cells inhibitor.

of phosphorylated NF- $\mathrm{B}-\mathrm{p} 65$ in the cells decreased, in a time-dependent manner. By contrast, the level of phosphorylated NF- $\kappa \mathrm{B}-\mathrm{p} 65$ expression in the negative control cells was comparable to that of total NF- $\mathrm{KB}$ expression (Fig. 1B).

$N F-\kappa B$-p 65-binding sites in the ADAMTS9 promoter. A previous investigation demonstrated that NFATc1 binding consensus sites may activate ADAMTS9 gene expression (2). In the present study, cloned human ADAMTS9 gene sequences were analyzed in order to investigate the involvement of other putative transcription factor binding sites in ADAMTS9 gene expression. The consensus DNA-binding sequence of NF- $\mathrm{BB}$ is
GGGRNNYYCC ( $\mathrm{N}=$ any base, $\mathrm{R}=$ purine, and $\mathrm{Y}=$ pyrimidine) (11). DNA sequences that were highly homologous to the consensus DNA-binding sequence of NF- $\kappa \mathrm{B}$ were identified in the ADAMTS9 genome data base (Fig. 2). In the present study, two sequences located -1335 and -1177 bp upstream of the transcription start site of ADAMTS9 were used for further analysis due to the ChIP experiments. Other sites defined as $-130,-460$ and -618 did not exhibit effective NF- $\kappa \mathrm{B}$ binding of ADAMTS9, according to the ChIP experiments (data not shown). Immunoprecipitation analysis was performed and the amplification of potential consensus sites was assessed via PCR amplification using the primers in Table I. 
NF-KB consensus motif: GGGRNNYYCC
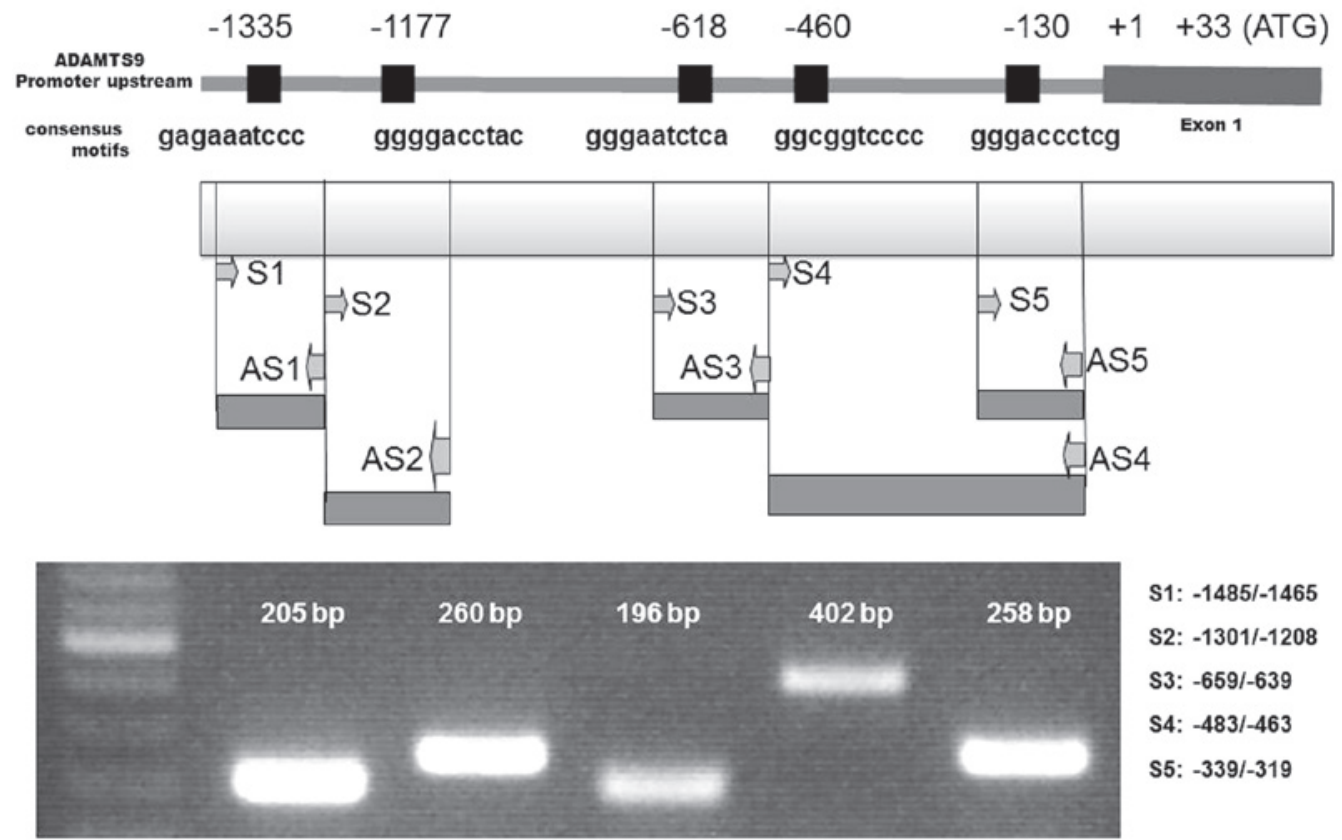

S1: $-1485 /-1465$

S2: $-1301 /-1208$

S3: $-659 /-639$

S4: $-483 /-463$

S5: $-339 /-319$

Figure 2. DNA sequences homologous to the consensus DNA-binding sites of NF-kB and their positions in the ADAMTS9 promoter region. Primers targeting the potential consensus sites are indicated below the genes. Electrophoresis was used to confirm the amplification of consensus sites using the primers in

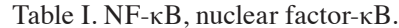

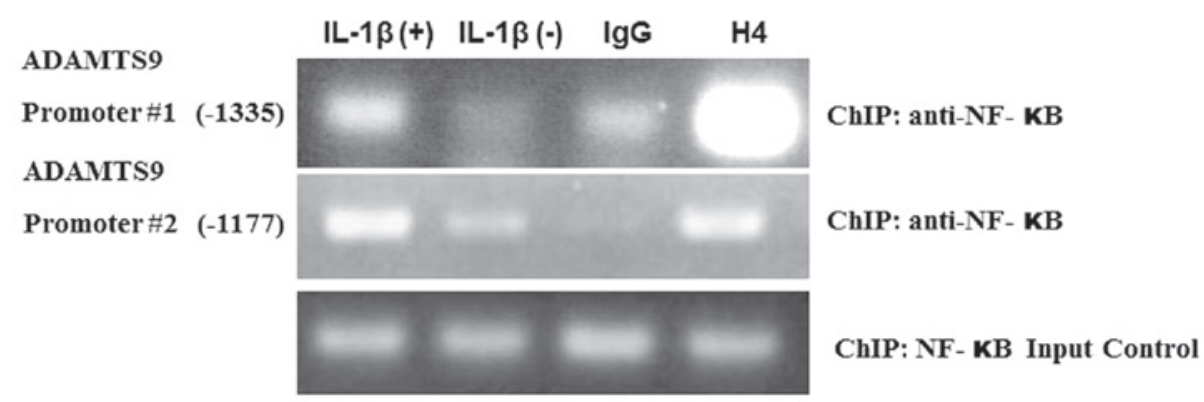

Figure 3. Activation of the ADAMTS9 promoter region. OUMS-27 cells were treated with $10 \mathrm{ng} / \mathrm{ml}$ IL-1 $\beta$ for 20 min and then fixed with $1 \%$ formaldehyde for $10 \mathrm{~min}$. A chromatin immunoprecipitation assay was performed using an anti-p65 antibody. DNA was PCR amplified using ADAMTS9 promoter-specific primers. IL-1 $\beta$, Interleukin-1 $\beta$; ADAMTS9, a disintegrin-like and metalloproteinase with thrombospondin type 1 motif 9; ChIP, chromatin immunoprecipita-

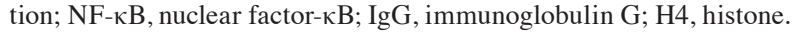

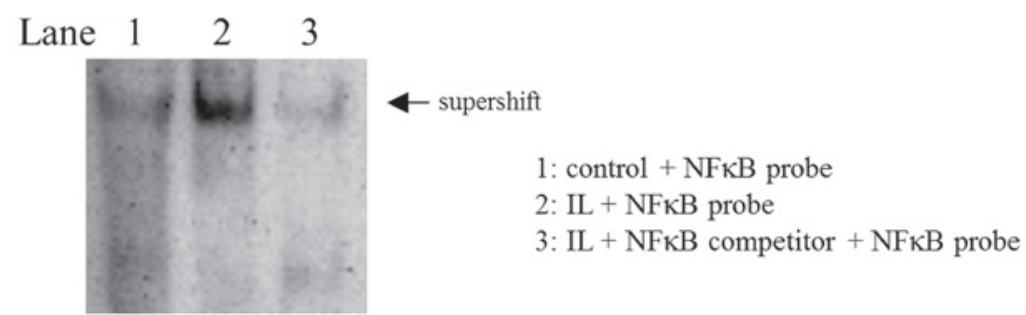

Figure 4. Confirmation of NF-kB-binding sites in the ADAMTS9 promoter region. OUMS-27 cells were treated with IL-1 $\beta$ for 20 min. An electromobility shift assay was conducted using biotin-labeled primers containing each of the homologous NF-kB binding sites. DNA extracts from IL-1 $\beta$-treated OUMS-27

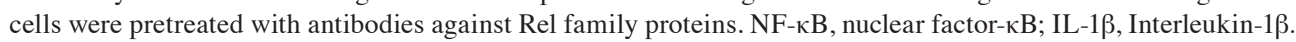

Following 20 min of OUMS-27 cell treatment with IL-1 $\beta$, ChIP analysis suggested that NF- $\mathrm{B}$ successfully bound with the ADAMTS9 promoter consensus sites, -1335 and -1177 (Fig. 3). However, NF- $\mathrm{BB}$ did not bind with the
ADAMTS9 promoter \#1 consensus site (-1335) in the negative control OUMS-27 cells (no IL-1 $\beta$ treatment). IgG was used as a negative control and $\mathrm{H} 4$ histone protein was used as a positive control for the experiment. For promoter \#2, there was 
decreased binding of NF- $\kappa \mathrm{B}$ in the IL-1 $\beta$ untreated cells, as compared with the treated cells at -1177 bp upstream of the ADAMTS9 promoter (Fig. 3).

In order to confirm the presence of NF- $\kappa \mathrm{B}$ binding sites in the ADAMTS9 promoter region an EMSA assay was performed. A supershift assay suggested that, following IL-1 $\beta$ treatment, NF- $\kappa$ B bound to ADAMTS9 promotors in OUMS-27 cells. However, in cells not treated with IL-1 $\beta, \mathrm{NF}-\kappa \mathrm{B}$ did not bind to ADAMTS 9 promotors. By contrast, in negative control cells, using a cold $\mathrm{NF}-\kappa \mathrm{B}$ competitor, there was no evidence of $\mathrm{NF}-\kappa \mathrm{B}$ binding to the ADAMTS9 promoters. In the positive control cells, only a 'free probe' was expressed (Fig. 4).

\section{Discussion}

The results of the present study suggested that the human ADAMTS9 promoter region exhibits $\mathrm{NF}-\kappa \mathrm{B}$ binding elements and may be a target gene for $\mathrm{NF}-\kappa \mathrm{B}$ gene expression. IL-1 $\beta$-induced NF- $\kappa \mathrm{B}$ is capable of binding with ADAMTS9 promoters in OUMS-27 chondrosarcoma cells. ADAMTSs are secreted proteinases, which are involved in cell adhesion, proteolytic shedding and cell signaling (12).

The ADAMTS9 gene is localized to chromosome 3p14.2 and is the most highly conserved member of the ADAMTS family. ADAMTS9 cleaves versican and aggrecan proteins, and may therefore be termed aggrecan. Previous studies have indicated that aggrecanases are associated with the development of a number of diseases, due their involvement in cell development, angiogenesis, cancer and inflammatory processes (13-15). In osteoarthritis and rheumatoid arthritis, ADAMTS9 is involved in inflammatory responses associated with cartilage damage $(13,15)$. Therefore, elucidation of the regulatory mechanisms underlying ADAMTS9 expression and activation is required. A number of studies have revealed that various signaling pathways, such as the mitogen-activated protein kinases (MAPK) pathway, are associated with the regulation of ADAMTS9 gene expression (3-5). ADAMTS9 gene expression was found to be downregulated following treatment with SB600125 and BAY 11-7085, which are inhibitors of MAPK and $\mathrm{NF}-\kappa \mathrm{B}$, respectively $(4,6)$. The phosphoinositide 3-kinase signaling pathway does not appear to be associated with ADAMTS9 gene expression (3). There is evidence to suggest that ADAMTS9 expression may be regulated by IL- $1 \beta$ and TNF- $\alpha$ treatment (4). A previous study demonstrated that, following IL- $1 \beta$ treatment of isolated chondrosarcoma and chondrosarcoma cells, ADAMTS9 expression was induced to a greater degree than that of all other aggrecanase genes (4). IL-1 $\beta$ may activate the expression of a number of inflammation-associated transcription factors. A previous study demonstrated that the transcription factor, NFATc1, is capable of activating the expression of ADAMTS9 following IL-1 $\beta$ treatment in human chondrocytes (5). The results of the present study suggested that $\mathrm{NF}-\kappa \mathrm{B}$ activation, following IL-1 $\beta$ treatment, is associated with ADAMTS9 expression in OUMS 27 cells.

$\mathrm{NF}-\kappa \mathrm{B}$ is involved in the activation of a number of genes that encode adhesion molecules, such as E-selectin. These molecules mediate leukocyte tethering and rolling, which is involved in acute and chronic inflammatory processes that are associated with inflammatory injury and rheumatoid artritis $(16,17)$. The present study demonstrated that the ADAMTS9 promoter region contains five NF- $\kappa$ B consensus binding sites at $-130,-460,-618,-1177$ and $-1335 \mathrm{bp}$. A previous study suggested that NF- $\mathrm{B}$ phosphorylation may be induced following IL-1 $\beta$ treatment in Jurkat cell lines derived from an immortalized line of T lymphocytes and HEK293 (human embryonic kidney cells) (7). In the present study, NF-кB-p65 was phosphorylated following IL-1 $\beta$ treatment of OUMS-27 cells. The results suggest that NF- $\mathrm{B}-\mathrm{p} 65$ phosphorylation may induce the binding of NF- $\kappa \mathrm{B}-\mathrm{p} 65$ to specific consensus sites of the ADAMTS9 promoter region at locations -1177 and $-1335 \mathrm{bp}$, following treatment with IL-1 $\beta$. According to the electrophoresis gel image (Fig. 3), this bond was most prominent at location -1335 bp, compared with location -1177 bp of the ADAMTS9 promoter region. By contrast, in negative control OUMS-27 cells, NF- $\kappa$ B did not bind to the ADAMTS9 promoter region.

In conclusion, the results of the present study suggested that the human ADAMTS9 promoter region exhibits NF- $\kappa \mathrm{B}$ consensus sites, which are potential targets for NF- $\mathrm{B}$ transcription factor binding. IL-1 $\beta$-induced NF- $\kappa \mathrm{B}-\mathrm{p} 65$ subunit binding to the ADAMTS9 promoter region in OUMS-27 cells. The present study provides a novel approach for ADAMTS9 gene-targeted therapy and ADAMTS9 inhibition. These results may be suitable for the development of treatment for a number of pathological conditions, including cartilage injury.

\section{Acknowledgements}

Dr T. Kunisida (Okayama University Graduate School of Medicine and Dentistry, Okayama, Japan) provided the OUMS-27 chondrosarcoma cell line.

\section{References}

1. Tortorella MD, Burn TC, Pratta MA, et al: Purification and cloning of aggrecanase-1: a member of the ADAMTS family of proteins. Science 284: 1664-1666, 1999.

2. Apte SS: A disintegrin-like and metalloprotease (reprolysin type) with thrombospondin type 1 motifs: the ADAMTS family. Int J Biochem Cell Biol 36: 981-985, 2004.

3. Uysal S, Ünal ZN, Erdoğan S, et al: Augmentation of ADAMTS9 gene expression by IL- $1 \beta$ is reversed by $N F-\varkappa B$ and MAPK inhibitors, but not PI3 kinase inhibitors. Cell Biochem Funct 31: 539-544, 2013.

4. Demircan K, Hirohata S, Nishida K, et al: ADAMTS-9 is synergistically induced by interleukin-1beta and tumor necrosis factor alpha in OUMS-27 chondrosarcoma cells and in human chondrocytes. Arthritis Rheum 52: 1451-1460, 2005

5. Yaykasli KO, Oohashi T, Hirohata S, Hatipoglu OF, Inagawa K, Demircan K and Ninomiya Y: ADAMTS9 activation by interleukin 1 beta via NFATc1 in OUMS-27 chondrosarcoma cells. and in human chondrocytes. Mol Cell Biochem 323: 69-79, 2009.

6. Xu YX, Pindolia KR, Janakiraman N, Chapman RA and Gautam SC: Curcumin inhibits IL1 alpha and TNF-alpha induction of AP-1 and NF- $\kappa$ B DNA-binding activity in bone marrow stromal cells. Hematopathol Mol Hematol 11: 49-62, 1997.

7. Chen D, Li X, Zhai Z and Shu HB: A novel zinc finger protein interacts with receptor-interacting protein (RIP) and inhibits tumor necrosis factor (TNF)- and IL1-induced NF-kappa B activation. J Biol Chem 277: 15985-15991, 2002.

8. Cogswell JP, Godlevski MM, Wisely GB, et al: NF-kappa B regulates IL-1 beta transcription through a consensus NF-kappa B binding site and a nonconsensus CRE-like site. J Immunol 153: 712-723, 1994.

9. Hoesel B and Schmid JA: The complexity of NF- $\mathrm{B}$ signaling in inflammation and cancer. Mol Cancer 12: 86, 2013. 
10. Barnes PJ and Karin M: Nuclear factor-kappaB: a pivotal transcription factor in chronic inflammatory diseases. N Engl J Med 336: 1066-1071, 1997.

11. Hayden MS and Ghosh S: Signaling to NF-kappaB. Genes Dev 18: 2195-2224, 2004.

12. Bret C, Hose D, Reme T, et al: Gene expression profile of ADAMs and ADAMTSs metalloproteinases in normal and malignant plasma cells and in the bone marrow environment. Exp Hematol 39: 546-557, 2011.

13. Demircan K, Yonezawa T, Takigawa T, et al: ADAMTS1, ADAMTS5, ADAMTS9 and aggrecanase-generated proteoglycan fragments are induced following spinal cord injury in mouse. Neurosci Lett 544: 25-30, 2013.
14. Lin EA, Liu CJ: The role of ADAMTSs in arthritis. Protein Cell 1: 33-47, 2010

15. Kevorkian L, Young DA, Darrah C, et al: Expression profiling of metalloproteinases and their inhibitors in cartilage. Arthritis Rheum 50: 131-141, 2004.

16. Zheng X, Zhu S, Chang S, et al: Protective effects of chronic resveratrol treatment on vascular inflammatory injury in streptozotocin-induced type 2 diabetic rats: Role of NF-kappa B signaling. Eur J Pharmacol 25: S0014-2999, 2013.

17. Choi YJ, Lee WS, Lee EG, Sung MS and Yoo WT: Sulforaphane inhibits IL-1 $\beta$-induced proliferation of rheumatoid arthritis synovial fibroblasts and the production of MMPs, COX-2, and PGE2. Inflammation 37: 1496-1503, 2014. 